\title{
Relações de Classe e Gênero na Escola: revisitando conceitos de igualdade, desigualdade, diferença, classe e gênero
}

Maria Mary Ferreira*

\section{Resumo:}

A proposta deste artigo é discutir os conceitos de igualdade, diferença, identidade, classe e gênero na perspectiva de refletir e entender como estes conceitos marcam a construção da identidade tendo a escola como lócus. Compreende-se que as desigualdades sociais se estabelecem a partir das relações de classe, raça e gênero que se entrecruzam com as diferenças culturais que por sua vez estão relacionadas ao reconhecimento e valorização do outro. Somos diferentes em função de vários fatores: raça/etnia, sexo, gostos, lugares onde habitamos, orientação sexual, entre outros pontos que nos diferenciam uns dos outros. Essas diferenças, porém, não devem ser tratadas de forma desigual, deve contribuir para marcar nossa identidade e fortalecer nossos laços e relações com o outro. Assim, ao refletir esses conceitos espera-se contribuir para ampliar o debate nas escolas e universidades espaços considerados fundamentais para alterar as relações de poder e de gênero com vistas à construção de uma sociedade de iguais.

Palavras-chave: Igualdade. Diferença. Classe Social e Gênero.

\footnotetext{
* Possui graduação em Biblioteconomia pela Universidade Federal do Maranhão (1981), Mestrado em Políticas Públicas pela Universidade Federal do Maranhão (1999) e doutorado em Sociologia pela Universidade Estadual Paulista (2006). Fez Estágio doutoral na Universidade de Coimbra em Portugal. Atualmente é professora adjunta da Universidade Federal do Maranhão.
} 


\section{Relations of Class and Gender at School: revisiting the concepts of equality, inequality, difference, class and gender}

\author{
Relaciones de Clase y Género en la \\ Escuela: volviendo a visitar conceptos \\ de igualdad, desigualdad, diferencia, \\ clase y género
}

\section{Abstract}

The purpose of this article is to discuss the concepts of equality, difference, identity, class, and gender to reflect on these concepts and understand how they mark the construction of identity having the school as their locus. It is understood that social inequalities are established from the relations of class, race and gender that intersect with cultural differences, which in turn are related to the recognition and appreciation of the other. We are different concerning several factors: race / ethnicity, gender, preferences, places where we live, sexual orientation, among other things that differentiate us from the others. These differences, however, should not be treated unequally, but they should help to mark our identity and strengthen our ties and relationships with the others. Thus, by reflecting on these concepts, we expect to contribute to broaden the debate at schools and universities, both seen as the key to change the relations of power and gender in order to build an egalitarian society.

Keywords: Equality. Difference. Social Class and Gender.

\section{Resumen}

La propuesta de este artículo es discutir los conceptos de igualdad, diferencia, identidad y género en la perspectiva de reflejar y comprender como estos conceptos marcan la construcción de la identidad con la escuela como lócus. Se comprende que las desigualdades sociales se establecen a partir de las relaciones de clase, raza y género que se interrelacionan con las diferencias culturales que a su vez están relacionadas con el reconocimiento y el aprecio del otro. Somos diferentes en función de varios factores: raza / etnia, género, preferencias, lugares en los que vivimos, orientación sexual, entre otros puntos que nos diferencian unos de otros. Estas diferencias, sin embargo, no deben ser tratadas de manera desigual, deben contribuir a marcar nuestra identidad y fortalecer nuestros vínculos y relaciones con los demás. Así, al reflejar estos conceptos se espera contribuir a ampliar el debate en las escuelas y universidades, espacios considerados como clave para cambiar las relaciones de poder y de género con el fin de construir una sociedad de iguales.

Palabras clave: Igualdad. Diferencia. Clase Social y Género. 


\section{Introdução}

Os esforços para construir uma sociedade sem desigualdades de gênero, raça e etnia tem sido intensivamente trabalhados no atual governo brasileiro a partir da aprovação do Plano Nacional de Políticas para as Mulheres e do Plano Nacional de Promoção da Igualdade Racial. Esses planos, porém, ainda não estão sendo efetivados nos contextos das escolas fato que deve ser objeto de preocupação do estado nas três instâncias: federal, estadual e municipal.

Ao refletirmos sobre a escola como espaço de construção de sujeitos, observamos que o processo de construção desses sujeitos segue caminhos muitas vezes tortuosos e contraditórios. Produzimos um discurso muitas vezes fantasioso e falacioso que demonstram o quão complexas têm sido as relações sociais no contexto da escola e em sala de aula.

A dificuldade de compreender a dimensão deste discurso se dá à medida que grande parte dos professores não consegue ainda se perceber como sujeito, não consegue estabelecer identidades com seu grupo social e não se percebem como educadores. É por esta razão as escolas no Brasil mesmo considerando as mudanças empreendidas na última década ainda se constituem um espaço de desigualdade e reprodução, como bem atestou Bourdieu (2003, p, 53):

Se considerarmos seriamente as desigualdades socialmente condicionadas diante da escola e da cultura, somos obrigados a concluir que a equidade formal à qual obedece todo o sistema escolar é injusta de fato, e que, em toda sociedade onde proclamam ideais democráticos, ela protege melhor os privilégios do que a transmissão aberta dos privilégios.

A partir deste autor, pode-se afirmar que a escola é um espaço de reprodução da desigualdade, na medida em que as práticas pedagógicas são pautadas em valores culturais que, em geral, colocam a classe dominante como modelo, como centro, ou seja, a escola ignora as diferenças socioculturais existentes em cada aluno e, em geral, trata como se todos viessem de uma mesma clas- se social. Assim, são ensinados conteúdos que levam os alunos a reproduzir conceitos e valores advindos de um grupo social que não é o deles.

Além disso, ao não considerar que as crianças e jovens, dependendo da forma como foram socializados, podem reagir mais positivamente a determinados métodos de ensino, a escola promove diferenciações que irão incidir em desigualdades.

É importante considerar que determinados conteúdos são mais bem compreendidos por determinadas crianças e jovens que tiveram acesso desde cedo às redes de internet, por exemplo, aos vídeos games, ao cinema e ao teatro, começaram a ler cedo, através da a literatura infantil disponível, que tem nos contos de fada um exercício de fantasiar o real. Os alunos que passaram por socialização com esses recursos têm maior facilidade de aprendizagem diferente dos que não tiveram acesso a eles.

Outro ponto importante que a leitura de Bourdieu (2003) nos esclarece é que os alunos que tiveram mais recursos nos processos educativos são apresentados pelo professor como modelo, como padrão, enquanto os outros são imediatamente inferiorizados, diminuídos frente àqueles que reagem mais rapidamente aos estímulos pedagógicos.

Nesta mesma direção, observa-se em relação ao gênero e de raça e etnia. No que se refere ao gênero, as representações criadas socialmente retratam as mulheres como seres menores, inferiorizadas, docilizados, mais afeitas a profissões que se integram no mundo do privado. Essas representações perpassam os muros da escola e levam para a sala de aula discursos e práticas que reproduzem valores conservadores que insistem em retratar as muIheres de forma inferior.

Por esta razão, é necessário repensar essas práticas na sala de aula, buscando métodos que valorizem cada aluno, independente do lugar, grupo social ou família a que este aluno pertença, independente das questões de gênero, de raça e etnia. Sabemos, porém, que embora a escola se fundamente em princípios da igualdade e da universalidade, o que se observa é que esta tem dificul- 
dade de entender como estes conceitos estão presentes no seu cotidiano. A proposta deste texto é refletir sobre esse problema à luz de alguns conceitos que nos instigam ao debate. Conceitos de igualdade, desigualdade, diferença, gênero e classe são fundamentais para nortear a construção de novas pedagogias que estimulem novas práticas no contexto da escola. Vamos então conversar sobre esses conceitos.

$\mathrm{Na}$ estrutura deste artigo, discutimos inicialmente o conceito de igualdade a partir de autores como Cassassus (2007) e Benevides (2004), os conceitos de diferença e identidade também são analisados neste texto a fim de entender sua importância para marcar a presença e entender que na construção da identidade estão implícitos diferença e reconhecimento. Somos diferentes em função de vários fatores: raça/etnia, sexo, gostos, lugares onde habitamos, orientação sexual, entre outros pontos que nos diferenciam uns dos outros. Essas diferenças, porém, não devem ser tratadas de forma desigual, devem contribuir para marcar nossa identidade e fortalecer nossos laços e relações com o outro. No texto, abordamos ainda os conceitos de classe e gênero considerados estratégicos para o debate sobre gênero na escola e fundamental para as mudanças que a sociedade necessita para alterar as relações de poder que perpassam todas as relações sociais e que interferem na cidadania das mulheres, daí a necessidade de refletir e construir mecanismo de alterá-las.

\section{Igualdade e Desigualdade: pontos para pensar}

No mundo ocidental em pleno século XXI ainda convivemos com uma cultura que reproduz modelos que em muitas situações retratam aspectos da antiguidade e do período medieval ao tratar determinados segmentos de forma indiferente, diferenciada e desigual. As mulheres, os/as negros, os/as indígenas, os homossexuais representam a parcela sub-representada na sociedade e, em muitas situações, não consultadas, fato que reflete os indicadores de representação nas esferas de poder em todos os estados brasileiros.

Para ilustrar esse ponto, olhemos a situação das mulheres na política pernambucana, paulista, sergipana e ma- ranhense. Quantas mulheres exercem o cargo de vereadoras nas câmaras municipais de São Luís, Aracaju, São Paulo? E perguntamos o que a escola tem como esse fato? A escola deve se preocupar com isso? Deve sim, porque é na escola que se reflete sobre os fatos sociais é também o local que se pode pensar e entender os porquês, em especial da igualdade. Antes de dizer, repetir ou reproduzir frases que reforçam os estereótipos que excluem as mulheres da política a partir de frases do tipo: “[...] Ah! É porque as mulheres não sabem fazer política! Elas não levam muito jeito! Política é lugar de homem, assim como o futebol! Será?"

Aparentemente é verdade, quando nos deparamos com apenas duas vereadoras entre os vinte e quatro eleitos para a Câmara Municipal de Sergipe e apenas quatro vereadoras entre os trinta e um vereadores eleitos para a Câmara Municipal de São Luís Maranhão nas eleições de 2012. No Congresso Nacional, temos apenas quarenta e cinco deputadas federais entre os quinhentos e treze deputados. O que esses números revelam, entretanto, é que existe uma desigualdade entre homens e mulheres no exercício do poder legislativo em todo o Brasil e que essa desigualdade é reflexo das relações de poder que esbarram no exercício da democracia.

Ao pensarmos o conceito de igualdade quase que imediatamente nossa mente nos leva a pensar o oposto: desigualdade. $O$ certo é que o conceito nos conduz a essa relação. Para se entender o termo desigualdade, é preciso relacioná-lo com a igualdade. Igualdade, portanto, é o oposto de desigualdade.

A compreensão desses dois conceitos pode ficar mais clara quando os relacionamos à questão de classe social. Para Karl Marx (ano), a desigualdade de classe é a geradora de todas as outras desigualdades, porque está relacionada ao capital (dinheiro) financeiro. É vista desta forma porque os detentores de capital são, também, os donos das propriedades e dos meios de produção, são os donos das terras, das plantações de sojas, das fazendas de gados das fábricas, das indústrias, dos meios de comunicação. São eles que detêm o poder e determinam as formas de socialização. 
A classe dominante, que detém os meios de produção, acumula a maior parte dos bens geradores de capital e assim promove a desigualdade social. A desigualdade é em grande parte gerada pela concentração de poder e dinheiro nas mãos dos capitalistas que controlam as nações.

A partir da compreensão sobre desigualdade de classe, observamos que outras desigualdades são decorrentes. É o caso das desigualdades culturais, tão bem estudadas por Bourdieu (2003), como mencionamos anteriormente. Esse autor considera que as desigualdades culturais são consideradas pontos demarcadores na compreensão da exclusão e isso se percebe claramente pela forma como homens e mulheres foram socializados. Para ele, o capital cultural estabelece diferenciações sociais à medida que os gostos e valores culturais adquiridos por cada um de nós no mundo social - ir ao teatro, ler um livro, assistir a um filme, ouvir um concerto musical, assistir a um espetáculo de dança- são elementos distintivos entre um e outro ser.

Outra explicação também importante para entender a oposição entre os dois termos é a de Casassus (2007). Para esse autor, o conceito de igualdade deve ser compreendido sob a perspectiva do direito, porém sem perder de vista que a desigualdade de renda repercute em outras desigualdades sociais.

As condições de vida refletem de forma muito presente nos indicadores de educação, razão por que "uma parte dos pobres termina o ensino fundamental, mas uma parte menor ainda termina o ensino médio, e uma porcentagem muito pequena tem acesso e termina o ensino superior" (CASASSUS, 2007, p.47).

Os dados apresentados pelo autor não estão muito distantes de nós, basta olharmos com atenção e questionar quantos dos nossos colegas que estudaram conosco na escola no ensino fundamental e no médio, quantos deles chegaram à universidade? Por que não chegaram? Muitos deles tiveram que trabalhar muito cedo, muitas colegas casaram cedo e tiveram que assumir os cuidados com os filhos e ao mesmo tempo trabalhar para sustentá-los, impedindo dessa forma de continuar os estudos.

Observemos que os dados apresentados por Casassus (2007) e pelo IBGE (2013) demonstram que o Brasil, mes- mo com todos os esforços realizados pelo Governo Luiz Inácio Lula da Silva e Dilma Roussef nos últimos doze anos, não conseguiu ainda superar as desigualdades sociais que são evidentes. Os índices de analfabetismo no Brasil refletem a crueldade dessas desigualdades que também é percebida a partir das regiões. Vejam que o analfabetismo no Brasil segundo o censo de 2010 está em torno de $9,63 \%$, no Maranhão, entretanto, quase $20 \%$ da população é analfabeto, fato que incide de forma muito direta nos indicadores de pobreza e qualidade de vida. Os dados revelam a face da desigualdade que tem na educação um dos fatores importantes para superá-la.

A dificuldade na superação das desigualdades sociais dá-se por vários fatores, entre eles citamos: a herança da escravidão, a desigualdade regional, a corrupção que desvia o dinheiro público de sua real função, como atestam os inúmeros casos de denúncias de desvios de recursos do Fundo Nacional de Desenvolvimento da Educação (FNDE), conforme denúncia registrada no site jusbrasil (DESVIO, 2014).

É o caso do Estado do Maranhão, em que um número considerável de prefeitos respondem processos por desvio de recursos públicos, a esse fato se juntam a ausência de políticas públicas capaz de inverter os indicadores de pobreza que atinge milhares de família maranhenses.

Por esta razão, a construção da igualdade deve ser uma meta a ser alcançada pelos governos, uma vez que "a igualdade é sempre uma dimensão social, não individual" reforça Benevides. Essa autora aponta quatro dimensões para compreender a igualdade na perspectiva democrática:

[...] - Igualdade diante da lei - é um pressuposto da aplicação concreta da lei, quer proteja, quer puna; - igualdade no uso da palavra, ou da participação política; - igualdade do direito à diferença, ou seja, o direito que todos igualmente têm de preservar sua identidade;- igualdade de condições econômicas - consideradas básicas para garantir a dignidade humana. (BENEVIDES, 2004, p.100, grifos nossos).

Ao abordamos a questão da igualdade, percebemos que no mundo em que vivemos não somos iguais e muitos exemplos apresentados ao longo deste texto que po- 
dem ilustrar essa assertiva. Não somos iguais no mundo do trabalho, no mundo da política, não somos iguais porque uns podem ir ao teatro e outros não, não somos iguais porque uns andam de automóvel, outros de ônibus, ou porque uns tem três carros e outros, somente uma bicicleta.

Esses exemplos podem ser compreendidos a partir das questões de classe social. E as desigualdades no mundo da política? Por que tão poucas mulheres entram na política? Por que tão poucos homens e mulheres negras chegam às profissões de médicos e engenheiros? Por que as pessoas idosas são consideradas incapazes após aposentadoria, por que os homossexuais são chamados de forma pejorativa? Esses questionamentos também se explicam pela questão de classe, mas principalmente, pela questão da cultura, de gênero, geração, pela questão étnico-racial ou ainda pela orientação sexual.

Os conceitos de igualdade, desigualdade e de gênero podem ser melhor compreendidos quando entendemos o conceito de diferença que amplia nossa visão para o atual contexto e como a sociedade tem contribuído para se pensar as relações sociais e os comportamentos sexuais.

\section{Entendendo a Diferença}

Em que momento somos diferentes uns dos outros? Em praticamente todos os momentos em nossos cotidianos. Estamos sempre reaprendendo, reelaborando, aperfeiçoando nossas práticas e nos diferenciando uns dos outros pelas nossas particularidades e modos de fazer determinadas coisas ou agir de diferentes maneiras dependendo dos estímulos que recebemos ou da forma como fomos socializados. Por isso somos diferentes. Mas, muitas de nossas diferenças são construções sociais incutidas como valores culturais e que vão sendo introjetadas em nossas mentes e assim vão se transformando em verdades.

Por que grande parte das mulheres veste saia e os homens vestem calças? Por que foi convencionado que saia é um vestuário feminino e calça é um vestuário mascu- lino, porém na Suécia e na Escócia e em alguns países do continente africano homens também vestem saia. Por quê? Porque isso faz parte da cultura desses povos. Os indígenas também vestem saia nos rituais e isso também é da cultura deles. Esses exemplos nos fazem compreender que somos diferentes. Somos diferentes, mas não somos desiguais! Somos diferentes em relação a alguém, ou a alguma coisa. Diferença e desigualdade não são a mesma coisa.

O conceito diferença está relacionado a várias questões: questões étnicas, de sexo, de idade, de orientação sexual, de gostos, de religião, de escolhas profissionais, diferenças físicas, alguns de nós somente conseguem ler com óculos, outros não conseguem ver, uns ouvem até o soar dos grilos em noite de inverno, outros somente conseguem ouvir com aparelho auditivo, uns somente andam de muleta, outros de cadeiras de roda, uns conseguem se expressar com todas as letras, outros somente conseguem usar algumas palavras.

Esses exemplos demonstram claramente que somos diferentes. O grande paradoxo é entender como essas diferenças são tratadas social e politicamente no conjunto da sociedade. Como é tratada na sala de aula. Por que é importante entender? Porque a desigualdade se instaura quando a diferença é afirmada. Vejam nas frases a seguir como essas questões são tratadas socialmente e como chegam na sala de aula.

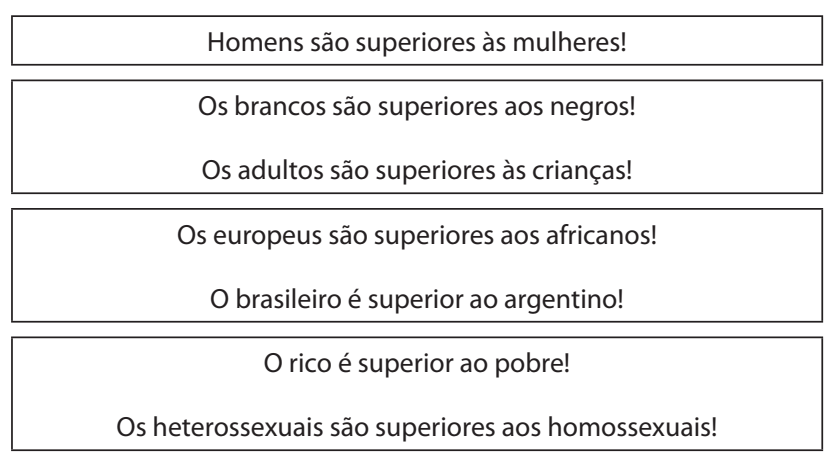

A desigualdade se estabelece quando é construída a partir da diferença e quando essa diferença é construída negativamente através da exclusão ou da marginalização daquela pessoa ou grupo social em relação a outra pessoa ou em relação ao grupo. 
Quando enfatizamos "sou negra!", estamos afirmando nossa negritude, mas estamos também enfatizando que não somos brancas, ou que somos diferentes das brancas. Quando dizemos sou carioca, maranhense, sergipano, pernambucana, só o fazemos pela necessidade de afirmar nossa identidade com os estados em que nascemos ou habitamos. A diferença, portanto, tem uma relação estreita com o termo identidade, é uma forma de marcar nossa presença e afirmar quem somos. Tomaz Tadeu Silva ao discutir esse conceito explica que "a diferença é como um produto derivado da identidade. A identidade é a referência, é o ponto original relativamente ao qual se define a diferença." (SILVA, 2003, p.76).

Identidade e diferença são vistas por Silva (2003) como mutuamente determinadas. São processos criados pelo ser humano "não podem ser compreendidos fora do sistema de significação nos quais adquirem sentido". Não são processos naturais, mas culturais. A afirmação da identidade e a marcação da diferença implicam sempre nas operações de incluir e excluir. Quando dizemos que somos isso, significa afirmar que não somos aquilo. "A identidade e a diferença se traduzem, assim, em declarações sobre quem pertence e sobre quem não pertence, sobre quem está incluído e sobre quem está excluído". (SILVA, 2003, p.82.)

Neste debate, muitos desafios são apontados, talvez o maior deles seja o de aprendermos a viver com o diferente e compreendermos que aquele diferente só é diferente porque estamos estabelecendo essas diferenças a partir do que aprendemos a valorizar ou desvalorizar. É importante compreendermos que fazemos parte de uma totalidade, mas que cada um de nós é único e o fato de ser único não nos torna mais importantes que o outro.

Esse desafio passa pela nossa formação ética e pela revisão dos nossos conceitos, uma vez que toda identidade exige reconhecimento, se não reconhecemos o outro como sujeito capaz, nós estamos então, nos sentindo superiores a ele ou ela.

A desigualdade e igualdade podem ser também compreendidas a partir dos conceitos de classe e gênero. Vejamos no item seguinte

\section{Relações de Classes: para entende os antago- nismos que nos separam a partir do capital}

As classes sociais fazem parte da estrutura social e com ela mantêm relações específicas. A concepção estrutural e dinâmica sobre as classes sociais foi desenvolvida por Marx e Engels. Para entender o conceito de classe social é importante estruturá-lo em três aspectos: filosófico, econômico e histórico e dentro de um enfoque estrutural - funcional e dinâmico. A compreensão do conceito conduz ao conhecimento das forças e antagonismos da sociedade, dos dinamismos sociais e das relações sociais. $O$ conceito só adquire significado como parte de uma teoria das classes sociais.

Compreende-se então que classe social é uma categoria histórica, visto que somente a entendemos no conjunto das relações que fazem a evolução e o desenvolvimento da sociedade. A existência de uma classe está em função da outra. As classes são parte integrante da dinâmica da sociedade, são forças que movem as transformações da sociedade e também se transformam no mesmo movimento em que se dá essa transformação social (STAVEHAGEN, 1980, p. 287).

As classes se referem a grupos de homens e mulheres, que se diferenciam pelo lugar que ocupam num sistema historicamente determinado de produção social, por suas relações com os meios de produção, relações estas que são, na maioria das vezes, reguladas por leis e normas que têm na sociedade capitalista o eixo norteador. É, portanto, o modo de produzir de uma determinada sociedade que a distingue das outras: suas estruturas de produção, suas especificidades e as formas de relação que os homens estabelecem uns com outros são o que formam as classes sociais.

As classes somente existem como parte de seu sistema, nunca isoladamente. As relações de classes se dão dentro de um sistema socioeconômico determinado, em que se opõem (dominantes e dominados), mas também estabelecem complementariedades e se ligam de forma dialética (exploradores e explorados) como parte integral do funcionamento de um todo. É importante compreender que os grupos humanos são as classes, e as relações de classe são as relações que se estabelecem entre eles. 
O que diferencia uma classe da outra, ou seja, uma classe que domina e outra que é dominada é o fato de que a primeira detém os meios de produção, isto é, são os donos das empresas, das fábricas, das terras, das máquinas, são os que dominam as tecnologias e os meios de comunicação. É a classe dominante quem compra a força de trabalho e nem sempre paga de forma justa basta observar a exploração imputada a inúmeras categorias: pedreiros, bancários. A classe dominante em geral apropria-se indevidamente das horas de trabalho dos trabalhadores e trabalhadoras que são explorados e não remunerados de forma justa. Essas horas não remuneradas favorecem o processo de acumulação de riqueza por parte da classe dominante que se traduz nas condições vida infinitamente melhor, no acesso ao ensino de qualidade, no acesso aos bens e serviços, inclusive aos bens e produtos culturais contribuindo para a sua hegemonia e domínio. Como afirma Marx (1988, p. 155):

A classe que dispõe dos meios de produção material dispõe, também, dos meios de produção intelectual, de sorte que os pensamentos daqueles para os quais são recusados os meios de produção intelectual são, ao mesmo tempo, submetidos a essa classe dominante.

As lutas e conflitos entre as classes expressam as contradições internas dos sistemas econômicos determinados. São elas que fazem os questionamentos às formas como os grupos humanos estão organizados para produzir a vida material, os valores e os serviços.

A discussão de classe pensada a partir de Karl Marx tende a explicar as relações desiguais existentes na sociedade pelo viés do capital, ou seja, pela acumulação de capital/dinheiro. O dinheiro é uma dos mecanismos de divisão da sociedade que cria e reforça as distâncias entre uma classe e outra. Esta divisão, porém, não é considerada a única forma de separação entre as classes. Para Bourdieu (2003), por exemplo, a separação entre as classes não se evidencia apenas pela acumulação do capital/dinheiro, mas também pelo capital cultural que tem como ponto de partida o desenvolvimento escolar, uma vez que "a acumulação de capital cultural exige uma incorporação que, enquanto pressupõe um trabalho de inculcação e de assimilação, custa tempo que deve ser investido pessoalmente pelo investidor" (BOURDIEU, 2003, p. 64), mediante o conhecimento formal embora como enfatiza o autor.

Assim, ao se discutir classe, não se pode perder de vista que a classe dos intelectuais (aqueles que estudaram e detêm capital cultural) pode não ter dinheiro, mas detém poder, dada a sua condição de conhecedor da sociedade em diferentes dimensões.

\section{Gênero: discutindo o conceito no contexto da escola}

As desigualdades sociais não se explicam apenas pela categoria classe, existem outras desigualdades que perpassam a sociedade. São as desigualdades como já mencionadas de gênero, raça e etnia, de geração, de opção sexual, desigualdade regional que muitas vezes reproduzimos em expressões do tipo "fulano é do interior" estabelecendo desigualdades em quem mora em São Luís, Bacabal, Cajari ou São Roberto' ou em Esperantina no Piauí ou ainda em Areia Branca (Sergipe).

Para compreender o conjunto de relações desiguais e diferenciadas é preciso se apropriar de alguns conceitos, é necessário refletir sobre os fenômenos, fazer leituras e observar bem os fatos históricos que ampliem nosso olhar sobre essa realidade. $O$ conceito de gênero nos permite compreender as desigualdades construídas a partir do sexo. Permite compreender as dimensões das desigualdades que estão além das questões relacionadas à condição financeira por exemplo. Permite entender porque tantas mulheres ainda sofrem violência doméstica e sexual e entender melhor porque as mulheres optam mais por profissões consideradas femininas: professoras, nutricionistas, bibliotecárias, assistentes sociais. Como podemos compreender esse conceito?

Na gramática, gênero, em sua concepção original, serve para designar indivíduos de sexos diferentes ou ainda coisas sexuadas, porém na perspectiva acadêmica o gênero é uma linguagem, uma forma de ordenar o mundo, que orienta a conduta das pessoas da maneira como elas vão se relacionar umas com as outras [...] "É mais 
do que uma maneira de como as pessoas se relacionam é também um jeito de olhar e compreender a realidade". (UNBEHAUM, 2005, p.4).

A discussão do conceito de gênero e sua incorporação nos diferentes campos: educação, sociologia, política, antropologia tem sido marcada por diferentes interpretações. Scott (1996) afirma que o conceito não gozava de uma compreensão única, nem detinha uma tradição teórico-epistemológica sólida, como o conceito de classe, isso tem se constituído um entrave haja vista a tradição marxista de nossas academias, mas, segundo Louro (2002, p. 228) "esse entrave não impediu de que ao conceito fosse incorporado o germe do debate e da crítica indispensáveis para o desenvolvimento de qualquer teoria".

Nas universidades esses estudos passaram a fazer veladas críticas à ciência rejeitando seu papel de neutralidade e objetividade, na qual "a positividade e o funcionalismo, eram a prática comum nas pesquisas na universidade brasileira até meados de 1985". (BRUSCHINI, 1992, 290). Essas críticas partem de análises de que nas instituições científicas foi criada uma cultura de gênero, que reforça o distanciamento das mulheres da ciência, assim como estigmatizou as classes sociais, que têm na burguesia os detentores dos meios de produção, ao interferirem na sociedade e disseminam ideias, cujo princípio era a desigualdade social.

De certo modo, o que tem imperado nos estudos e pesquisas em nossas universidades, e em particular, nas maranhenses, é a cultura do masculino, o que pode ser constatado em diversos estudos a exemplo dos voltados para a temática sobre trabalho que em geral não percebem as mulheres como produtivas e muitos desses estudos continuam reproduzindo uma sociedade em que as mulheres são invizibilizadas uma vez que a captação dos dados nesse tipo de estudo levam em conta, quase sempre, a regularidade do trabalho, a continuidade, integralidade e a remuneração formal, segundo regras da economia capitalista. Dessa forma, desconsideram o trabalho feminino que em geral se caracteriza como:

[...] descontínuo, irregular, remunerado informalmente, muitas vezes não remunerado, tem sido ocultado pelos dados, fazendo com que as mu-
Iheres aparecessem como não trabalhadoras, com não cidadãs, reforçando a ideologia dominante de que o trabalho feminino não era representativo e/ ou relevante. (FERREIRA, 2002, p. 167).

Vejam por exemplo o caso das trabalhadoras rurais, que só recentemente passaram a ser reconhecidas como trabalhadoras. Anteriormente essa categoria era considerada exclusivamente masculina embora as mulheres, desde tempos imemoriais, tenham no cuidado com a terra uma das suas principais atividades. $O$ mesmo ocorre com o trabalho doméstico, que por se constituir uma atividade preponderantemente realizada por mulheres de forma exaustiva, "não tem sido contabilizado como uma atividade econômica". (FERREIRA, 2002, p. 296).

Como se vê, os dados ocultam questões importantes do trabalho feminino, visto que não levam em conta a dupla jornada de trabalho, nem a importância e necessidade dos cuidados com as crianças. Para Passos (2001, p.27), a ruptura com o modelo cognitivo racionalista tende a fugir das categorias universais e abstratas que estruturam o conhecimento incluindo novas categorias de produção do saber até então rechaçadas e consideradas atípicas ou excepcionais. Dessa forma Ferreira $(2002$, p. 167) propõe:

\begin{abstract}
aproximar a teoria da prática e romper com essas categorias dentro desse universo de dominação que vivenciamos nas universidades e que tem sido a marca dos estudos de gênero. São esses estudos que possibilitaram a ampliação e amadurecimento de reflexões sobre a mulher. Estes estudos específicos responderam alguns problemas levantados no discurso feminista, e foram imprescindíveis na luta para ampliação dos direitos femininos.
\end{abstract}

É certo que ainda há diferentes interpretações e usos do conceito de gênero, entretanto as pesquisadoras feministas, entre as quais me incluo, trabalham com o conceito aliado à teoria feminista que vê a mulher como sujeito, considera, portanto que o gênero é uma categoria que deve ser desenvolvida para contestar a naturalização da diferença sexual, dar uma nova conotação aos estudos acadêmicos ou às visões androcêntricas de perceber a sociedade e romper com a visão naturalizada do feminino e do masculino. Infelizmente, muitos estudos 
incorporam o conceito de forma limitada "tomando-o como um mero substituto para o termo mulher, desprezando assim, suas potencialidades analíticas mais radicais". (LOURO, 2002, p. 229).

Vale a pena, portanto apresentar a essência do conceito, tal qual $\mathrm{Scott}^{2}$ desenvolveu. A autora destaca três elementos importantes para apresentar o tema: parte do princípio de que a sociedade se percebe através de símbolos e, em se tratando das mulheres, estes símbolos evocam representações múltiplas e frequentemente contraditórias, a exemplo das representações que se fazem de Eva/Maria ou puta/santa. A partir de valores morais vão demarcando modelos de mulheres que contribuem para estigmatizá-las ora enaltecendo, ora condenando-as. (FERREIRA, 2010)

Outro elemento sugerido pela autora são os chamados conceitos normativos expressos nas doutrinas políticas, educativas, jurídicas, científicas ou religiosas que tomam a forma de oposição binária, afirmando de modo categórico e inequívoco o sentido de ser homem e ser mulher, de masculino e feminino sem considerar que o ser homem ou ser mulher é uma construção social e que existe uma posição clara entre dominador e dominada, o que não explica que esta relação é fruto de posições normativas e, por esta razão, não devem ser compreendidas a partir dos chamados consensos, e sim, de conflitos que se estabelecem nas relações sociais.

O terceiro elemento que Scott trabalha são as relações de gênero construídas a partir das chamadas instituições e organizações sociais entre as quais destacamos a Escola, os Partidos políticos, a Família e a Igreja, entre outros. Para Ferreira (2010, p. 259), "estas organizações tem sido verdadeiros sustentáculos do modelo patriarcal que eleva a figura masculina, a condição de decidir sobre os destinos das mulheres, excluindo-as dos processos históricos e das representações sociais".

Existem diferentes perspectivas teóricas que lidam com o conceito de gênero. Este tem sido apropriado de forma distinta por inúmeras áreas e suas teorias, entretanto a historicidade das relações de gênero, sua natureza dialética e seu caráter mutável formam um campo para a reflexão, a crítica e a reconstrução dessas relações, num processo contínuo de mudanças que exige da parte de educadores/as a apropriação de saberes e conhecimentos capazes de orientar um processo de superação das relações de desigualdade, de desvalorização, de discriminação e exclusão social das mulheres.

Dessa forma, é importante compreender o exercício de uma pedagogia como um canal que problematize as realidades de gênero, que possibilite a compreensão crítica dos processos de desigualdade e a construção da equidade de gênero no âmbito da educação, que favoreça a construção de novas relações culturais referentes às condições das mulheres e dos homens na sociedade.

Esse enfoque pedagógico poderá ser exercido através de mesas e rodas de diálogos sistemáticos dentro e fora da sala de aula, entre alunos/as e professores/as e a comunidade escolar, abordando temas que suscitem o debate com capacidade de confrontar a cultura dominante com as realidades vivenciadas. Esse trato pedagógico possibilitará a apropriação de novos conhecimentos e a construção de relações democráticas, libertárias e multiculturais.

\section{Conclusão}

Os conceitos acima mencionados chamam a atenção para a complexidade que envolve as relações de classe e de gênero enquanto relações socioculturais e de poder construídas historicamente. Esses conceitos também apontam para um campo de tensão existente nas relações entre os grupos humanos com marcas de sub-representação social, tendo por base os preconceitos, as discriminações e as desigualdades.

Como trazer o debate para a sala de aula? Como essas questões são percebidas entre os alunos em cada escola e curso universitário? Como podemos conduzir uma discussão de forma educativa? Uma atitude pedagógica na perspectiva de uma educação para a diversidade envolve primeiramente o reconhecimento da escola como um espaço de discussão crítica e superação de valores, tradições e hábitos que reforcem a negação de uma visão conservadora e patriarcal e busque uma vivência multicultural. 
É necessário que os/as educadores/as se apropriem de conhecimentos hoje disponíveis sobre identidades, igualdade, diferença, gênero, no intuito de construir pedagogias que levem os alunos no ambiente escolar a problematizar as relações dominantes existentes e construir um olhar multicultural para uma intervenção libertária e democrática.

O espaço escolar, assim como o espaço universitário, deve ser trabalhado no sentido de que alunos/as e professores/as possam sentir-se pertencendo a esse espaço, incluindo os elementos que lhes favoreça a apropriação dos processos construídos/desconstruídos/reconstruídos do ponto de vista dos valores afirmativos a uma pluralidade cultural e étnica. Trata-se do exercício de uma pedagogia que reconheça e considere os/as alunos/ as na sua historicidade, na valorização das diferenças, superando dessa forma os conceitos essencialistas e os tratando como categorias socialmente construídas no decorrer dos discursos históricos.

Há ainda uma invisibilidade ou invisibilidade subalterna dos diversos grupos sociais negros, indígenas e mulheres baseados em preconceitos étnicos raciais, em relações de gênero, instituídos e manifestados no cotidiano das escolas, das universidades e na sociedade como um todo. Porém, os cientistas sociais e os educadores com formação em gênero estão demonstrando como ações pedagógicas podem contribuir enormemente para transformar esse tipo de relação.

O desafio é repensar a visão dominante instituída (colonialista, escravista) a partir do envolvimento e participação dos/as alunos/as num processo reflexivo sobre os padrões de exclusão instituídos, com foco na construção de um pensamento libertário. É importante compreender que as desigualdades são fruto das relações de classe e também da cultura de gênero que se constituem relações de poder.

Como tratar essa questão dentro da escola e da universidade? Primeiro, dotá-la de currículos com conteúdos pertinentes a essas problemáticas tratadas numa perspectiva crítica que valorize as identidades constituintes da sociedade.
Para tanto, é necessário desenvolver ações pedagógicas e ações culturais pautadas na diversidade, com exercícios, em sala de aula, de vivências que favoreçam o estudo dos conceitos de gênero, de raça e etnia, na perspectiva de valorização de múltiplos sujeitos e a desconstrução dos estereótipos que foram atribuídos historicamente a esses diversos grupos sociais.

Uma saída é tornar os planos nacionais de igualdade de raça e etnia e de gênero visíveis no contexto das escolas e universidades, para que sejam incorporados aos Projetos políticos pedagógicos de cada e escola e cada curso universitário. Essa medida contribuirá enormemente para estabelecer mudanças e melhorar as relações sociais.

\section{Notas}

1 Munícipios que fazem parte do Estado do Maranhão.

2 SCOTT, Joan. Gênero: uma categoria útil para análise histórica. 3. ed. Recife: SOS Corpo e Cidadania, 1996. 19p.

\section{Referências}

BENEVIDES. Maria Victoria. Cidadania e questão de gênero. In: Educar para igualdade: gênero e educação escolar. São Paulo: Coordenadoria Especial da Mulher. Secretaria de Educação, 2004. p. 93-106.

BRASIL. Secretaria Nacional de Politicas para as Mulheres. II Plano Nacional de Políticas para as Mulheres, 2007.

Secretaria Nacional de Politicas para as Mulheres. Mais mulheres no poder: contribuição à formação políticas das mulheres, 2010.

BRUSCHINI Cristina. Uso de abordagens quantitativas em pesquisa sobre relações de gênero. In COSTA, Albertina de Oliveira, MUSCHINI, Cristina. Uma questão de gênero. Rio de Janeiro: Rosa dos Tempos, p. 289-299, 1992.

BOURDIEU, Pierre. A escola conservadora: as desigualdades frente à escola e à cultura. In: NOGUEIRA, Maria Alice; CATANI, Afrânio. Pierre Bourdieu: escritos de Educação. 5. ed. Petrópolis: Vozes, 2003.p.39-64.

DEMO, Pedro. Professor e Pesquisa: positividade da aprendizagem. 2009. Disponível em: <http://pedrodemo.sites.uol.com. br/textos/profpesq5.html> Acesso em: 20 abr. 2011.

DESVIO de Verbas do Fnde. Disponível em: <http://www.jusbrasil.com.br/topicos/548496/desvio-de-verbas-do-fnde>. Acesso em: 24 mai. 2014. 
DIÉGUEZ, Carla. O que é classe social? 2008. Disponível em: <http://www.sinprorp.org.br/clipping/2008/081.htm> . Acesso em: 28 abr. 2011.

FERREIRA, Maria Mary. A/o profissional da informação no mundo do trabalho e as relações de gênero. In: CASTRO, César Augusto. Ciência da informação: múltiplos discursos. São Luís: EDUFMA; EDUFAMA, 2002. p. 161-18.

FERREIRA, Mary Maria. Educação feminina e gênero. O difícil percurso para romper com a submissão das mulheres. In: CASTRO, César Augusto. (Org.) Leitura, impressos e cultura escolar. São Luís: EDUFMA,2010. p.249-265.

LOURO, Guacira Lopes. Gênero: questões para educação. In: BRUSCHINI, Cristina; UNBEHAUM, Sandra G. (ors). Gênero, democracia e sociedade brasileira. São Paulo: Fundação Carlos Chagas; Ed. Três. 2002. p.225-242.

MARX, Karl. O Capital: crítica da Economia política. 14. ed. Rio de Janeiro: Bertrand, 1994. v. 1

MARX, Karl. A produção da sociedade: fundamentos da história. In. IANNI, Otavio. Marx: sociologia. 6. ed. São Paulo Ática, 1988.

NOGUEIRA, Juliana Keller. FELIPE, Delton Aparecido. TERUYA, Tereza Kazuco. Conceitos de gênero, etnia e raça: reflexões sobre a diversidade cultural na educação escolar. In: <http:// www.fazendogenero.ufsc.br/8/sts/ST1/Nogueira-Felipe-Teruya_01.pdf >. Acesso em: 08 mai. 2011

PASSOS, Elizete. As políticas e os saberes: a construção do gênero nas universidades do Norte e Nordeste e as repercussões nos campos social e político. In: FERREIRA, Mary, Álvares, Maria Luzia Miranda, Santos, Eunice Ferreira, (Orgs.) Os poderes e os saberes das mulheres: a construção do gênero. São Luís: EDUMA, Salvador: REDOR, 2001. 445 p. p.21-54.

PASSOS, Elizete (org). Um mundo dividido: o gênero nas universidades do Norte e Nordeste. Salvador: UFBA, 1997, 286 p.

RELATÓRIO de Desenvolvimento Humano para a América Latina 2010. Disponível em: <http://hdr.undp.org/en/media/PR4-HDR10-RegRBLAC-PT-rev2.pdf>. Acesso em: 26 abr. 2011.

SAFIOTTI, Heleiete I. B. Violência de gênero no Brasil contemporâneo. In: MUÑOZ - VARGAS, Mônica. Mulher brasileira é assim. São Paulo: Rosa dos Tempos 1995. 151 p.

STAVENHAGEM, Rodolfo. Classes Sociais e Estratificação Social. In Martins, João de Souza e Foracchi, Marialice (Org.). Sociologia e sociedade. Rio de Janeiro: Livros Técnicos e Científicos, 1980. p. 281-296.

UNBEHAUM, Sandra. Entendendo o que é Gênero. In: Ecos: comunicação e Sexualidade. 2005. Disponível em: <http://www. prr3.mpf.gov.br/noticias/diversidade/textos/entendendogenero.pdf>. Acesso em: 30 abr. 2011.
SCOTT, Joan. Gênero uma categoria útil de análise histórica. 1996. Disponível em: http://www.dhnet.org.br/direitos/textos/ generodh/gen_categoria.html> Acesso em: 20 jun. 2012.

Recebido em: 02/03/2014

Aceito em: 10/04/2014

Publicado em: 30/04/2014 